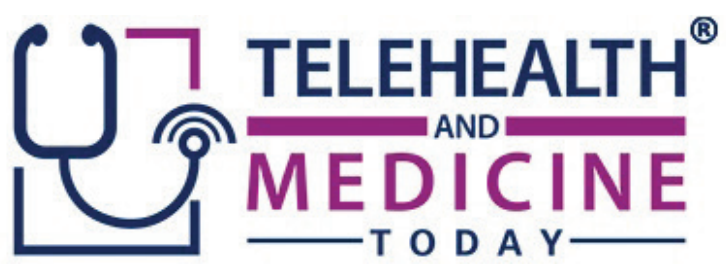

\title{
Using the BELT Framework to Implement an mHealth Pilot Project for Preventative Screening and Monitoring of Pregnant Women in Rural Burkina Faso, Africa
}

\author{
Antonia Arnaert, Norma Ponzoni, Hamidou Sanou, Noufou Gustave Nana
}

Affiliations: McGill University, Montreal, Canada; Institut de Formation et de Recherche Interdisciplinaire en Sciences de la Santé et de l'Education (IFRISSE), Burkina Faso, Africa

Corresponding Author: Antonia Arnaert, N, MPH, MPA, PhD, Associate Professor, McGill University, Ingram School of Nursing, 680 Sherbrooke West, Office 1906, Montreal, Quebec, Canada H3A 2N7, Email: antonia. arnaert@mcgill.ca

Keywords: Africa, Antenatal Care, BELT, Burkina Faso, Community Health, Framework, Internet Connectivity, mHealth, Postpartum Monitoring, Pregnancy, STREAMS, UN-Sustainable Development Goal \#3

Section: Methodologies

Introducing mHealth in resource-poor communities is not without technical, financial, and infrastructural challenges. Even today, little is known about the process of implementing sustainable mHealth services in these regions. The Broadband/Bandwidth, Education/ Environment, Leadership, \& Technology (BELT) framework helps guide stakeholders in identifying the core contextual elements that ensure successful implementation and organizational readiness. Hence, this paper describes challenges experienced when implementing the Strengthening Relationships and Enhancing Access to Maternal Services (STREAMS) project using this framework, in a rural community in Burkina Faso, Africa.
Methods and Findings: A focused ethnography using participant observation documented implementing the STREAMS process through the use of descriptive field notes. Despite having a champion who drove implementation, challenges that arose were mainly due to problems of Internet connectivity and a lack of participants' baseline computer skills, which had negative consequences on the initial training sessions and subsequent service delivery.

Conclusions: Availability of limited information on the rural context/demographics and similar mHealth projects in Burkina Faso led to a misfit between the initial plan and the contextual reality. Having access to this type of 
background information is especially important to the success of mHealth initiatives providing humanitarian aid.

$\mathrm{I}$ n 2015, Burkina Faso in sub-Saharan West Africa began working toward new health targets under the UN-Sustainable Development Goal \#3 (SDG-3): "ensure healthy lives and promote the well-being for all at all ages" (Table 1). Under this goal, Burkina Faso aims to reduce child mortality, improve maternal healthcare, and promote the health and empowerment of women. One of the strategies to achieve this goal is the involvement of community health workers living in rural villages to facilitate delivery of healthcare services. ${ }^{1,2}$ Aligned with this strategy, the current project Strengthening Relationships and Enhancing Access to Maternal Services (STREAMS), funded by Grand Challenges Canada, facilitates the relationship between primary care nurses/ midwives working in a community health center, or Centre de Santé et Promotion Sociale(CSPS), and community health workers in remote villages using technology-enabled home visits to provide antenatal support.

\section{Table 1. UN Sustainable Development Goal \#3} (SDG-3)

- Ensure health and well-being for all, at every stage of life.

- Address all major health priorities, including reproductive, maternal, and child health; communicable, noncommunicable, and environmental diseases; universal health coverage; and access for all to safe, effective, quality, and affordable medicines and vaccines.

- More research and development, increased health financing, and strengthened capacity of all countries in health risk reduction and management.
To address accessibility to quality healthcare services, mHealth initiatives are increasingly being used in Africa, especially in the domain of maternal health..$^{3-5}$ Like other African countries, Burkina Faso has increased its use of mHealth; however, these initiatives remain at an embryonic stage. mHealth has been used in a number of pilot projects, but without large-scale deployment due to a lack of sustained funding.

Benefits associated with mHealth include increased access to healthcare and health information; increased cost-efficiency of service delivery; and improved ability to diagnose, treat, and track diseases. ${ }^{6}$ Maternal mHealth projects have, for instance, been implemented to achieve healthier pregnancy, ${ }^{7}$ for postpartum monitoring, ${ }^{8}$ or to improve skilled care at delivery. ${ }^{9}$ It is suggested that mHealth initiatives are successful because they allow for early detection and referral to a healthcare provider, which can decrease maternal mortality by approximately $50 \% .{ }^{10}$ It is expected that mHealth will continue to contribute to meeting the SDG targets for child and maternal health, a continuation of the preceding UN-Millennium Development Goals. ${ }^{11-13}$

Introducing mHealth to resource-poor communities is not without technical, financial, and infrastructural challenges. ${ }^{14}$ Today, little is known about the process of implementing sustainable mHealth services in low- and middle-income countries. In addition, projects that fail to meet initial goals typically go unreported. ${ }^{15}$ Understanding why programs struggle to improve their chances of success is essential. Hence, this paper describes the challenges experienced when implementing the project STREAMS, using the BELT framework, in Diapangou's CSPS and its associated villages in the eastern region of Burkina Faso (Figure 1). 


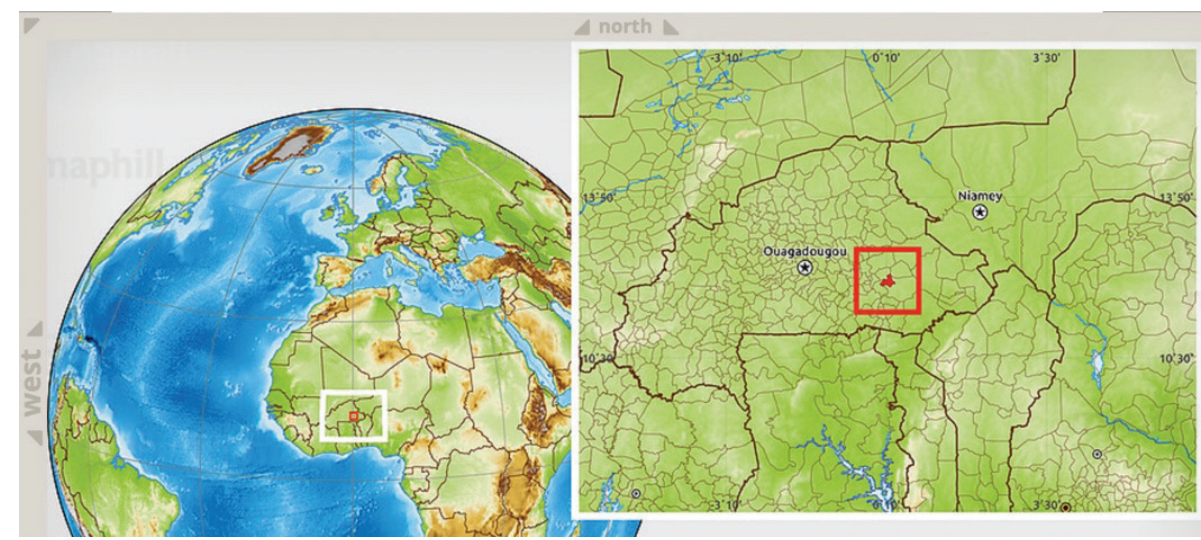

Figure 1-Burkina Faso, Africa.

Source: Maphill. http://www.maphill.com/burkina-faso/gourma/diapangou/maps/physical-map/

\section{METHODS}

STREAMS was implemented in January 2018 as a 1-year collaboration between local health authorities in the health district of Fada-N'Gourma and CSPS of Diapangou, a Canadian-based mHealth software vendor, and researchers from Burkina Faso and Canada. The region of Diapangou covers an area of about $573 \mathrm{~km}^{2}$ and includes 31 villages and 11 hamlets. The village of Diapangou, which shares the name of the region, is located $17 \mathrm{~km}$ (10.5 miles) from Fada-N'Gourma and $203 \mathrm{~km}$ (126 miles) from Ouagadougou, the capital of Burkina Faso. ${ }^{16,17}$ In Diapangou, there are three ethnic groups (the Gourmantches, the Mossi, and the Peuhls) practicing three religions (Animism, Islam, and Christianity). The prominent language is Gourmantchéma, followed by the Moré language, which is spoken by the Mossi community. Three villages (Bianargou, Lilitayanli, and Comboari) covered by the CSPS Diapangou were recruited for this project.

To address the reluctance of mothers to avail themselves of care by their local CSPS until late in their pregnancy, the community health workers of these villages were equipped with smart phones and portable medical equipment, such as blood pressure monitoring devices and glucometers.

Using their smart phones, community health workers engaged in regular screening and monitoring of pregnant village women and entered these data manually into a cloud-based telemonitoring platform, which was transferred wirelessly and monitored by the CSPS nurses/ midwives.

In addition, in the initial iteration of this project plan, community health workers, using a laptop computer, were able to web conference with CSPS nurses for mentorship and support. In addition to mHealth support, pregnant women continued to receive standard care - four antenatal care (ANC) visits during the course of their pregnancy.

IRB approval, obtained in January 2017 from entities in both Canada and Burkina Faso, focused on documenting the research assistant's experiences in implementing the mHealth services and acting as a participant observer through the use of descriptive field notes. These observations were recorded from January-May 2018, while the research assistant was residing in Diapangou. The field notes were content 
analyzed using Elo and Kyngäs's ${ }^{18}$ framework. Coding and categorization, using the BELT framework, were refined and confirmed for accuracy and consistency. Appropriate steps were taken to enhance the trustworthiness of the findings.

\section{RESULTS}

Existing frameworks used in mHealth/ telemedicine service implementation generally focus on the evaluation component rather than encompassing the planning and set-up of these services, which can be as complex in nature given the various inputs and outputs, activities, outcomes, and stakeholders involved. ${ }^{19}$ As an alternative, the BELT framework guides healthcare providers, decision-makers, and researchers in identifying the core contextual elements that must be in place to ensure successful implementation and organizational readiness. ${ }^{20}$

As stated earlier, the BELT acronym stands for Broadband/Bandwidth, Education/Environment, Leadership, \& Technology, as these have been identified as the recurrent areas of difficulty in implementation in developed and emerging countries. From a metaphorical perspective, BELT represents a loop, in which these identified elements are interdependent. Any break in this loop ultimately influences implementation. Below the BELT is applied in the context of the implementation of the STREAMS project.

\section{BELT.: Broadband/Bandwidth}

Broadband and bandwidth are generally used to describe the quality and speed of an Internet connection. Today, with the ubiquity of mobile technology, this element of the framework also includes the notion of "coverage"- the use of mobile telecommunication networks as an alternative source of Internet. Inherent to bandwidth, regardless of the source of Internet, is the understanding that the quality of the signal affects the speed of data transfer.

In early 2017, the Burkina Faso government embarked on the first phase of a nation-wide fiberoptic infrastructure that will interconnect the 45 provinces, thereby reducing access disparity among rural regions. ${ }^{21,22}$ While good news for Burkina Faso as a whole, current work on this infrastructure accounts for the frequent instability of connectivity nationally, both rural and urban. In rural regions, connectivity is fragile and varies broadly. For example, with regard to STREAMS, a more reliable Internet connection is available in the city, FadaN'gourma, via cybercafés that offer fiber Wi-Fi compared to the $3 \mathrm{G}$ mobile signal available in Diapangou. While slower compared to $4 \mathrm{G}$ technology, mobile $3 \mathrm{G}$ network coverage has been the only viable Internet option to sub-Saharan Africans since 2013 due to the existing poor fixed-line infrastructure..$^{23}$ Because STREAMS was implemented in a region where fiber Internet is not available, the community health workers' smart phones have prepaid data SIM cards with a specific number of units for airtime and Internet connectivity. Similarly, the CSPS laptop connects to the mobile network using a USB connector.

Throughout the planning of STREAMS, the authors recognized that connectivity would be a challenge; however, the full scope of the problem became evident only after the research assistant was onsite for implementation. Initially, we were comforted by the fact that in the event of variable connectivity, data could be uploaded to the platform offline. In other words, patient data could be collected and stored on the mobile phone temporarily. Then, when connectivity was reestablished, data would be synced back to the cloud server. However, even the local Burkina Faso research team, which operates mostly out 
of urban settings, had limited knowledge of the local, rural reality and how infrequent or nonexistent connectivity could be.

Constrained by the limitations timing, availability, and research budgets, connectivity was not tested before purchasing of equipment. During the implementation phase it became evident that connectivity was a serious impediment to the project. For example, during the initial 2-day training of CSPS nurses on the use of the telemonitoring platform, as the laptops did not yet have the required units to charge the USB connectors, the research assistant showed creativity by generating WI-FI hotspot connections using two $3 \mathrm{G}$ mobile phones to connect the laptops to the Internet. Despite this intervention, connectivity remained poor, causing him to move the team to Fada-Ngourma where the connection was slightly better. Overall, in both Diapangou and Fada-Ngourma, connectivity remains variable and unreliable, which causes uncertainty for project activities requiring access to the Internet. Currently, community health workers and nurses are documenting patient information on paper and then traveling to FadaNgourma periodically to enter the data onto the platform. One nurse summed it up well by saying, "The project is really good, but it is the network that will cause us a problem."

\section{BELT: Education/Environment}

The letter "E" in the BELT framework has a dual purpose. It represents the educational component and the notion of adjusting to the sociocultural environment or context where mHealth/ telemedicine interventions are implemented.

With regard to education on using the telemonitoring platform, the research assistant received three online sessions with the software vendor. Training consisted of an explanation of the platform's features, how to create profiles for patients and professionals, and the programming components of the tele-home visits, including scheduling home visits and configuring alerts, which are automatic notifications when specific patient data are outside expected parameters. These parameters were validated with experts in perinatal care.

In addition to this training, the research assistant was in constant communication with the vendor for additional clarification and support when he began training the nurses/midwives and community health workers separately on the use of the platform. The timing of this communication was sometimes challenging due to the difference in time zones between Burkina Faso (on Greenwich Mean Time) and Canada (4 hours earlier).

While the initial plan was to offer the CSPS nurses/midwives 2 days training on the use of the platform for monitoring purposes, it became evident that more foundational knowledge on how to use a laptop was required to prepare them for this training, for example, turning on and off the computer properly, accessing Google Chrome, entering the platform via the vendor's desktop icon, and logging-in to their monitoring profile using their password.

As a group, they were slow in typing, likely reflecting a general lack of familiarity with computers. As one nurse stated, "We have never had to work with computers, apart from using them to stream movies." In addition, using the glucometer was a challenge as the nurses had never had access to this equipment. As reported by one participant, "At the training school, we are told about these tools, but do not have the opportunity to use them."

To address this problem, the head nurse was trained by the regional physician on safe use of a glucometer, disposal of lancets, and so on. 
He subsequently trained the other healthcare professionals. To reinforce their knowledge, practice sessions on previously learned skills were incorporated. Overall, the nurses/midwives were excited to learn, and this created a positive and friendly learning environment. Some of their motivation stemmed from the realization that this equipment would stay in the CSPS after the project.

The 2-day training session of the community health workers started with understanding the use of smartphones. As this was relatively nonexistent, the research assistant had to demonstrate turning the phone on and off; accessing the keyboard, and differences between the numeric and alphabet keypad; how to use the "@" symbol in an email; and where to insert the SIM card.

Then, they were taught to recognize and access the software vendor's mobile app. Educational videos complemented this training. Because Google accounts were not yet created, community health workers used the research assistant's account.

On day 2, a theoretical session was organized with the head nurse to illustrate the use of the blood pressure monitoring devices and the glucometer. Generally, the community health workers were eager to learn. One went so far as to memorize all the steps involved, yet required reassurance from the research assistant that he would be available if the need arose.

The sociocultural environment (the other representation of the "E" in the BELT framework) must not be neglected. While technology brings us together geographically, when planning telemedicine services in an environment different from one's own, it is essential that the cultural context be taken into account to respectfully integrate existing systems.

One priority is to facilitate integration among local resident starting from the planning phase. However, even in a geographically small country like Burkina Faso, there is wide cultural diversity in the form of various spoken languages and religions. In this study, the research assistant did not speak Gourmantchéma, the local language of the majority in Diapangou. However, he had support from a local midwife who translated into French.

The linguistic barrier also arose between the nurses/midwives and patients, as three local languages are commonly spoken. To compound the linguistic barriers, illiteracy among the general population is common. This sometimes impacted the choice of community health workers and members of the advisory committee.

With regard to these two groups of participants, another cultural difference was the importance of the collective agreeing to the nominations and having representation across religious. This made selection a considerable honor.

Oftentimes, the village chief spoke for the collective; therefore, their approval was obligatory, which reinforced the notion of hierarchy. This importance of hierarchy also influenced obtaining approval for conducting the study in the community of Diapangou, with approval required first at the highest level, the General Secretary of the Ministry of Health, then the Regional Director of Health for the district of Fada-Ngourma, and so on.

Despite having set aside funds, another unexpected cultural norm was the lengthy 
negotiations and haggling in establishing compensation or stipends for health professionals to cover their time for the educational sessions, their travel/meal expenses, and hiring a replacement while they were in training.

Even locally, there can be a lack of consistency between governmental policy and cultural norms. For example, in Burkina Faso, there are four funded ANC visits for pregnant mothers, something that only a small minority of women comply with. However, as explained by one community health worker, "There are two women in (the village of) Comboari who refuse to go to the CSPS (despite their pregnancy) because their belly is not big enough." In summary, projects are stronger when there is very good understanding and adaptation to local contexts.

\section{BELT: LEADERSHIP}

In STREAMS, the research assistant functioned as a project champion and was recruited based on his interest in mHealth, prior experience in a similar study in Burkina Faso, and technological savvy.

A major force in the success of this project was the dynamic nature of the research assistant, who was an effective problem-solver and a strong advocate with the ability to build a local team. In addition, local partnership with Burkina Faso's Institut de Formation et de Recherche Interdisciplinaire en Santé (IFRIS) was essential for logistics and oversight.

\section{B.E.L.T.: Technology}

Within the BELT framework, technology is a broad concept that is not limited to information and communication technologies and related infrastructures such as hardware, software, cloud-based storage, and so on. Technology also encompasses a country or an organization's general infrastructure such as access to electricity, transportation, and so on.

Despite recent improvements by the Burkina Faso government to expand the electric grid to rural sectors, regular access to electricity was a challenge. Participants experienced difficulties recharging their mobile phones, relying on payper-use charging stations.

There have been no complaints regarding functionality of the smart phones. However, the initial plan of having devices save data offline until there was an opportunity to sync with the server has been problematic. The devices do not regularly have access to the Internet in all parts of the village, and therefore do not sync with the server unless the community health worker finds an area within their designated region with $3 \mathrm{G}$ connectivity.

In addition, the research assistant had difficulty configuring the profiles of the community health workers and patients in the telemonitoring platform and viewing these profiles once created - a problem that required a great deal of support from the software vendor. It remains unclear if the difficulties with the software were related to the limited connectivity, as these issues did not occur on the laptop using Google Chrome.

Initially, the telemonitoring platform was available only in English, so the software vendor had to quickly translate the interface into French for this project. Later, a request was made to translate the software interface into all local Diapangou languages, something that the vendor could not accommodate.

\section{DISCUSSION}

Lessons learned during development and implementation of the STREAMS project 
Table 2. Lessons from the STREAMS project

\begin{tabular}{|l|l|}
\hline $\begin{array}{l}\text { Lessons } \\
\text { assessment }\end{array}$ & $\begin{array}{l}\text { Contribution to success } \\
\text { - } \begin{array}{l}\text { A preliminary onsite needs assessment must be conducted by } \\
\text { researchers knowledgeable in the domain of mHealth }\end{array}\end{array}$ \\
\hline Recruit a project champion & $\begin{array}{l}\text { - A local clinician champion must understand local norms, } \\
\text { expectations/barriers, hierarchy within the healthcare system, and } \\
\text { so on. }\end{array}$ \\
\hline $\begin{array}{l}\text { Assess health literacy and } \\
\text { computer skills }\end{array}$ & $\begin{array}{l}\text { Understanding baseline skills is critical for developing content and } \\
\text { scheduling the duration of training }\end{array}$ \\
\hline Ensure good communication & $\begin{array}{l}\text { Fundamental to project planning, implementation, and follow-up } \\
\text { Communication between the local team and researchers abroad is } \\
\text { crucial }\end{array}$ \\
\hline
\end{tabular}

are listed in Table 2. These can guide future projects in rural areas, which may be underserved by the Internet.

To complement the existing guidelines and recommendations for the provision of mHealth/ telemedicine services, the BELT framework is an easy mnemonic that guides a systematic environmental assessment of an organization's readiness, which can foster successful implementation. Generally, limited information is publicly available on preimplementation environmental scans, which could be helpful in guiding clinicians or administrators in the planning phase. Unfortunately, this leads to many making the same type of error, wasting resources, and occasionally placing services at risk. If there was better knowledge dissemination in this area, managers could take advantage of the "lessons learned" by their peers and not have to "reinvent the wheel."

Unfortunately, process data on implementation of services are infrequently published. Yet, more process and contextual information from projects/services implemented in developed and emerging countries would inform similar projects, leading to more efficient planning and development of sustainable services. In the same vein, funding agencies and journals are considerably outcomefocused, which, while important, can deter researchers from spending time documenting challenges confronted during implementation.

Specific to the STREAMS project, the authors had a dual challenge during the planning phase. There was little information on the Burkina Faso rural context/demographics and scant information on similar mHealth projects within these regions. Moreover, having access to this background knowledge is important within the context of humanitarian aid initiatives, where foreign agents often contribute to the planning of services.

In summary, having a tool such as the BELT framework is beneficial to clinicians, researchers, and policy-makers. However, more research should be dedicated to support the set-up of mHealth services and its related evaluation, as this is a complex endeavor. Finally, guiding frameworks, such as the BELT applied here in an initial step of development, requires further 
testing and evaluation in order to design a useful tool that has ubiquitous pertinence.

Acknowledgement: The authors thank all women for their participation in this project. We are also grateful to the management of the CSPS Diapangou that supported the implementation of this project.

Funding Statement: This work was supported by the Grand Challenges Canada under Grant number R-ST-POC-1706-03334. The funders had no role in study design, data collection and analysis, decision to publish, or preparation of the manuscript.

Conflict of interest: The authors declare no conflict of interest.

Author contributions: All authors equally contributed to this publication.

\section{REFERENCES}

1. Maurice Y, Cheick B, Ourohiré M, et al. Use of mobile phone to promote governance and equity within the health system: Experience of rural health district in Burkina Faso. J Healthc Commun. 2016;1:3. https://doi.org/10.4172/24721654.100017

2. Redick C, Faich Dini HS, Long LA. The current state of community health worker training programs in sub-Saharan Africa and South Asia: What we know, what we don't know, and what we need to do. 2014 [cited 2017 August 7]. Available from: http://1millionhealthworkers.org/ files/2013/01/1mcommunityhealthworker_ mPowering_LitReview_Formatted. compressed.pdf

3. Al Dahdah M, Desgrées Du Loû A, Méadel C. Mobile health and maternal care: A winning combination for healthcare in the developing world? HPT. 2015;4:225-31.
4. Bagayoko CO, Sacko A, Sangare M, Anne A, Fieshi M. L'utilisation de la telephonie mobile pour ameliorer le systeme de remontee et du traitement des donnees sur le paludisme dans le district sanitaire de Kolokani au Mali. Guinée Médicale. 2013;80.

5. Gurol-Urganci I, de Jongh T, VodopivecJamsek V, Atun R, Car J. Mobile phone messaging reminders for attendance at healthcare appointments. CDSR. 2013;5(12). https://doi. org/10.1002/14651858.CD007458.pub3.

6. Mechael P, Batavia H, Kaonga N, et al. Barriers and gaps affecting mHealth in low and middle-income countries: Policy white paper. Center for Global Health and Economic Development (CGHED) with mHealth Alliance. 2010 [cited 2017 June 2]. Available from: http://www.globalproblems-globalsolutionsfiles.org/pdfs/mHealth_Barriers_White_ Paper.pdf

7. Ngabo F, Nguimfack J, Nwaigwe F, et al. Designing and implementing an innovative SMS-based alert system (RapidSMS-MCH) to monitor pregnancy and reduce maternal and child deaths in Rwanda. PAMJ. 2012;3:31.

8. Andreatta P, Debpuur D, Danquah A, Perosky J. Using cell phones to collect postpartum hemorrhage outcome data in rural Ghana. Int $J$ Gynaecol Obstet. 2011;113:148-51.

9. Lund S, Hemed M, Nielsen BB, et al. Mobile phones as a health communication tool to improve skilled attendance at delivery in Zanzibar: A cluster-randomised controlled trial. Int J Gynaecol Obstet. 2012;119:1256-64.

10. Musoke M. Maternal health care in rural Uganda: Leveraging traditional and modern knowledge systems. Indigenous Knowledge Notes. 2002;1-4.

11. Moahi KH. ICT and health information in Botswana: Towards the Millennium Development Goals. Information Development. 2009; 25:198-206. 
12. Noordam AC, Kuepper BM, Stekelenburg J, Milen A. Improvement of maternal health services through the use of mobile phones. TMIH. 2011;16:6226.

13. The World Bank. Information and communications for development 2012: Maximizing mobile. Washington, DC: World Bank; 2012.

14. Brinkel J, Krämer A, Krumkamp R, May J, Fobil J. Mobile phone-based mhealth approaches for public health surveillance in sub-Saharan Africa: A systematic Review. Int J Environ Res Public Health. 2014;11:11559-83. https://doi.org/10.3390/ ijerph111111559

15. Meyers DJ, Filkins M, Bangura AH, et al. Management challenges in mHealth: Failures of a mobile community health worker surveillance programme in rural Nepal. BMJ. 2017;0:1-7. https://doi. org/10.1136/bmjinnov-205/-000102

16. Tourisme au Burkina Faso (n.d.). La commune rurale de Diapangou. [cited 2018 July 8]. Available from: http://www. burkinatourism.com/La-commune-ruralede-Diapangou.html

17. Moyenga PM. Production cotonnière et développement rural au Burkina Faso: Controverses et réalité. Cas du département de Diabo dans la province du Gourma (Unpublished Master's Thesis). Université de Ouagadougou, Burkina Faso, Africa. [cited 2018 July 8]. Available from: https://www.memoireonline. com/09/10/3855/m_Production-cotonniereet-developpement-rural-au-Burkina-Fasocontroverses-et-realite-Cas-du-d8.html

18. Elo S, Kyngäs H. The qualitative content analysis process. $J$ Adv Nurs. 2008;62(1):107-15.

19. Hebert M. Telehealth success: Evaluation framework development.
Stud Health Technol Inform. 2001;84(Pt 2):1145-9.

20. Schlachta-Fairchild L, Mitra Rocca, Elfrink Cordi V et al. Chapter 8: Telehealth and applications for delivering care at a distance. In: Nelson R, Staggers N, editors. Nursing informatics: An interpersonal approach for health practitioner. St. Louis, MO: Elsevier; 2016.

21. TWeb Africa. Construction begins on Burkina Faso's US\$ 180m fibre optic backbone. 2017 [cited 2018 July 8]. Available from: http://www.itwebafrica. com/networks/872-burkina-faso/242004construction-begins-on-burkina-fasosus180m-fibre-optic-backbone

22. BuddeComm Intelligence Report. Burkina Faso-Telecoms, mobile and broadbandStatistics and analysis. February, 2018 [cited 2018 July 8]. Available from: https:// www.budde.com.au/Research/BurkinaFaso-Telecoms-Mobile-and-BroadbandStatistics-and-Analyses/?r=51

23. ITU-International Telecommunication Union Study on international Internet connectivity in sub-Saharan Africa. March, 2013 [cited 2018 June 16]. Available from: https://www.itu.int/en/ ITU-D/Regulatory-Market/Documents/ IIC_Africa_Final-en.pdf

Copyright Ownership: This is an open access article distributed in accordance with the Creative Commons Attribution Non Commercial (CC BY-NC 4.0) license, which permits others to distribute, adapt, enhance this work non-commercially, and license their derivative works on different terms, provided the original work is properly cited and the use is noncommercial. See: http://creativecommons. org/licenses/by-nc/4.0. 